\section{REFERENCES}

Butt, E. M., Nusbaum, R. E., Gilmour, T. C., and DiDio, S. L. (1958). Amer. F. clin. Path., 30, 479.

Cotzias, G. C. (1962). In Mineral Metabolism, vol. 2B, edited by C. L. Comar and F. Bronner, p. 417. New York.

Cox, D. W. (1966). \%. Lab. clin. Med., 68, 893.

de Duve, C. (1963). In Ciba Foundation Symposium on Lysosomes, edited by A. V. S. de Reuck and M. P. Cameron, p. 1. London.

Evans, G. W., and Wiederanders, R. E. (1967). Amer. F. Physiol., 213, 1177 .

Gault, M. H., Stein, J., and Aronoff, A. (1966). Gastroenterology, 50, 8. Goddfischer, S. (1967). Nature (Lond.), 215, 74.

Goldfischer, S., and Moskal, J. (1966). Amer. F. Path., 48, 305.

Gubler, C. J., Brown, H., Markowitz, H., Cartwright, G. E., and Wintrobe, M. M. (1957). \%. clin. Invest., 36, 1208.

Heimann, R. (1965). F. Path. Bact., 90, 479.
Hunt, A. H., Parr, R. M., Taylor, D. M., and Trott, N. G. (1963). Brit. med. Э., 2, 1498 .

Lindquist, R. R. (1967). Amer. F. Path., 51, 471.

Papavasiliou, P. S., Milier, S. T., and Çotzias, G. C. (1966). Amer. Y. Physiol., 211, 211.

Parr, R. M., and Taylor, D. M. (1964). Biochem. 7., 91, 424.

Peters, R. A. (1966). In The Biochemistry of Copper, edited by $\mathrm{J}$. Peisach, P. Aisen, and W. E. Blumberg, p. 175. London.

Ravin, H. A. (1961). 7. Lab. clin. Med., 58, 161.

Sass-Kortsak, A. (1965). Advanc. clin. Chem., 8, 1.

Scheuer, P. J., Thorpe, M. E. C., and Marriott, P. (1967). F. Histochem. Cylochem., 15, 300 .

Snell, F. D., and Snell, C. T. (1949). Colorimetric Methods of Analysis, 3rd ed., vol. 2, p. 107. Princeton, New Jersey.

Worwood, M. (1967). Ph.D. Thesis, University of London.

Worwood, M., and Taylor, D. M. (1967). In Nuclear Activation Techniques in the Life Sciences, I.A.E.A. Symposium, p. 501. Vienna.

\title{
Hepatic Artery Infusion Chemotherapy in Hepatoma
}

\author{
J. L. PROVAN,* M.B., B.SC., F.R.C.S. ; J. F. STOKES, † M.D., F.R.C.P. ; D. EDWARDS, $\ddagger$ M.B., M.R.C.P., F.F.R.
}

\begin{abstract}
Summary: Three patients with inoperable malignant hepatomas were treated by intra-arterial infusion of fluorouracil. In each case the treatment gave relief of symptoms : there was striking relief of pain in two cases.

Preoperative angiography is essential, but the technical problems are relatively minor.

The response of the tumours to chemotherapy is sufficiently encouraging to justify greater efforts for early diagnosis.
\end{abstract}

\section{Introduction}

Though surgery has a place in the treatment of primary carcinoma of the liver (Borman et al., 1961; McWilliam, 1961 ; Wilson et al., 1964 ; Lawrence et al., 1966 ; Lin, 1966 ; Chan, 1967), partiai hepatectomy still remains a formidable operation, with a mortality of up to $30 \%$ even in experienced hands (Schweizer and Howland, 1960 ; Brunschwig, 1963 ; Smith and Sherlock, 1964 ; Lin, 1966). In many cases resection is not possible because both lobes of the liver are involved by tumour. For these reasons alternative approaches to therapy require consideration.

Nelson et al. (1966) reported no significant beneficial effect in a series of 21 cases of hepatoma treated by oral fluorouracil, thiotepa, methotrexate, vincristine, or melphalan compared with a series of 18 controls, while Papac and Calabresi (1966) found no response to intravenous infusion of floxuridine. Intra-arterial infusion has proved more successful in the hands of Lawrence (1965), who reported objective improvement lasting for three to four months in two out of four cases, while Ariel and Pack (1967) favoured combined intra-arterial treatment with chemotherapy and radioactive isotopes. They pointed out that most cases of liver cancer are nourished via the hepatic artery and described two techniques, one by retrograde catheterization through a femoral artery and one, involving laparotomy, by an approach through the right gastroepiploic artery. Gorgun and Watne (1967) infused two hepatomas with methotrexate by the latter route and noted reduction in size of the liver and return of temperature to

\footnotetext{
- Senior Lecturer in Surgery, University College Hospital Medical School, Lonaon W.C.1.

Consultant Physician, University College Hospital, London W.C.1.
Consultant Radiologist, University College Hospital, London W.C.1.
}

normal ; they concluded that "significant palliation may occur after prolonged methotrexate infusion." Rochlin and Smart (1966) noted regression in two out of four hepatomas treated by hepatic artery infusion with fluorouracil via a catheter introduced through the brachial artery, though Byron et al. (1961) found no response in two hepatomas similarly treated with nitrogen mustard.

Most of the cases in the series described by these authors were of secondary carcinoma, and no distinction is made between the symptoms caused by this condition and those of primary hepatic carcinoma. It is, however, common experience that metastatic liver cancer is often painless, while if pain is present it is usually not a dominant feature of the illness. On the other hand, in primary carcinoma of the liver, several authors (Schupbach and Chappell, 1952 ; MacDonald, 1957 ; Nett and Gilbert, 1966 ; Nelson et al., 1966 ; Chan, 1967) have stressed the importance of pain in the symptomatology of the disease in adults. This feature alone makes it more important to palliate hepatoma than secondary carcinoma.

We report here three cases of hepatoma treated by intraarterial infusion of fluorouracil, which produced striking relief $₹$ of pain in two instances and disposed of lesser pain in the 은 other.

\section{Case 1}

A 47-year-old Lebanese merchant from Sierra Leone was origin- $N$ ally admitted to the Hospital for Tropical Diseases, London, under N the care of Dr. J. H. Walters in June 1967. Diabetes had been $\sigma$ discovered nine months previously but was well controlled by $500 \mathrm{mg}$. of tolbutamide t.d.s. For three months he had suffered increasing right upper abdominal and lower chest pain and had lost $\mathbb{D}$ weight. His liver was much enlarged, hard, and tender, and there? was no bruit over it. The spleen was not palpable and there was no ascites or jaundice. The E.S.R. was $96 \mathrm{~mm}$. in one hour (Westergren) and the plasma albumin $2.8 \mathrm{~g} . / 100 \mathrm{ml}$. Liver scan $\mathbb{\Phi}$ showed a large liver with irregular uptake. Needle biopsy showed $\frac{\rho}{\Phi}$ an anaplastic hepatocellular carcinoma.

His pain was very severe and needed $300 \mathrm{mg}$. of pentazocine for 2 its control. A catheter was passed through the right femoral artery 8 into the coeliac axis on 4 July and the liver was perfused with? $250 \mathrm{mg}$. of fluorouracil daily up to $6 \mathrm{July}$, when the dose was increased to $500 \mathrm{mg}$. daily until 24 July (total dosage $10 \mathrm{~g}$.). His pain was dramatically relieved within two days and the liver became? quickly softer and smaller.

He returned to Freetown on 28 July but died in November 1967. 


\section{Case 2}

A 66-year-old Hong Kong Chinese man who had lived in Britain for the previous 17 years attended the outpatient clinic in July 1966 on account of upper abdominal discomfort and distension for a few weeks and loss of half a stone $(3.2 \mathrm{~kg}$.) in weight. The liver was enlarged, hard, and tender, with two prominences on its anterior surface. There was no jaundice, the spleen was not palpable, and there was no ascites. He had a past history of pulmonary tuberculosis, but needle biopsy of the liver showed no acid-fast bacilli, grew no tubercle bacilli on culture, and showed no diagnostic histological changes.

Plasma bilirubin and alkaline phosphatase were normal, but the serum albumin was low at $2.5 \mathrm{~g} . / 100 \mathrm{ml}$. Liver scan showed at least two filling defects in the liver, and laparotomy was undertaken on 8 August. Three hepatic masses were found, the larger two of which were in the right lobe and were necrotic in the centre. Histobogy showed hepatocellular carcinoma. On 22 August a catheter was passed through the right femoral artery into the coeliac axis, a hepatic angiogram taken, and infusion of fluorouracil $500 \mathrm{mg}$. daily begun and continued until 19 September (total dosage $14 \mathrm{~g}$.). Ropeated blood checks during this time showed no deterioration of Hiver cell function and no depression of bone marrow. His appetite improved, he regained his lost weight, and his upper abdominal discomfort disappeared. The physical signs in the liver did not materially change. When last seen, in January 1968, he was subjectively well and working, and the liver was palpable as before.

\section{Case 3}

A 61-year-old Pole first complained of abdominal pain in 1961. Investigation at University College Hospital at this time revealed a large liver, biopsy of which showed early portal cirrhosis, His pain became progressively more severe and was felt in the right upper abdomen and lower chest. He was readmitted in March 1967 for further investigation. At this time the pain was relieved only by lying flat and bore no relation to food or meals. He had noted a mass in the right upper abdomen for three months and occipital headache had been present for one month before admission. The liver was enlarged, hard, and tender, with no bruit audible over it. The right lobe contained an orange-sized mass. There were no ascites, splenomegaly, or signs of liver failure. The E.S.R. was $54 \mathrm{~mm}$. in one hour, the plasma aspartate aminotransferase 83 Karmen units/min./ml., and the alkaline phosphatase slightly raised. Liver scan showed a large area of diminished uptake in the right lobe, and a hepatic arteriogram confirmed the presence of an avascular lesion at this site and did not show avascular masses in the rest of the liver.

Because of the apparently solitary lesion in the right lobe laparotomy was undertaken on 24 April 1967 with the intention of performing a right hepatic lobectomy. However, the left lobe was involved by multiple tumours and no procedure was undertaken apart from biopsy of one of the tumours. This confirmed the presence of malignant hepatoma. On 5 May a catheter was introduced into the coeliac axis via the right femoral artery and infusion of fluorouracil in a dosage of $250 \mathrm{mg}$./day was begun. The infusion was discontinued on 30 May after a total dosage of $6.25 \mathrm{~g}$. During the period of infusion his liver function showed no deterioration and there was no depression of bone marrow activity as indicated by platelet and white cell counts. On two occasions after removal of the catheter slight bleeding occurred from the skin puncture, which had become infected with Staphylococcus pyogenes. The bleeding was easily controlled by digital pressure and a pressure bandage. The liver became softar, regressed to half its size, and his pain was entirely relieved. However, he gradually lapsed into a semiconscious state, thought to be due to cerebral metastases, and died on 3 July 1967. Permission for necropsy was not obtained.

\section{Technique}

A green KIFA catheter with a preformed terminal curve about $3 \mathrm{~cm}$. in diameter is introduced percutaneously over a flexible guide wire into a femoral artery (Seldinger, 1.953; Odman, 1958). The catheter is advanced in the aorta under fluoroscopic control to the lower dorsal region with the guide wire protruding a few inches beyond the catheter tip. In this way the terminal catheter curve is obliterated and engagement of the catheter in branches of the abdominal aorta is avoided. At the level of D 12 the guide wire is withdrawn into the catheter lumen and the terminal catheter curvature thus re-formed. The degree of curvature may be varied by progressive advancement or withdrawal of the guide wire. The tip of the curved catheter is moved up and down the anterior wall of the aorta at the level of D 12 and L 1 until it is seen to engage in the coeliac axis, its correct positioning being confirmed by means of an injection of $5 \mathrm{ml}$. of contrast medium. Triosil $75 \%$ (sodium metrizoate) 20 to $25 \mathrm{ml}$. is then rapidly injected by hand pressure and a series of films taken at 2 per second for three seconds to demonstrate the arterial phase and at a rate of 1 per second for 15 seconds to demonstrate opacification of the liver, spleen, and the portal venous system. When necessary the anteroposterior views are supplemented by oblique views.

Once correctly positioned the catheter position remains remarkably stable. The maintenance of a correct catheter position was confirmed on return to the ward by taking an anteroposterior film with a portable apparatus after the injection of $10 \mathrm{ml}$. of contrast medium. This procedure was repeated at intervals during the period of infusion, but in no case was the catheter dislodged.

On the patient's return to the ward a litre bottle of normal saline, to which has been added the dosage of fluorouracil (5-10 mg./kg. body weight) together with $100 \mathrm{mg}$. of heparin, is connected to the catheter and suspended by a hook from the wall or ceiling at a height sufficient to overcome the systemic arterial pressure. This volume is run in over 24 hours and repeated daily. Daily checks of white cell and platelet counts are made for the first week and continued on alternate days thereafter.

\section{Radiological Findings}

In two of the patients (Cases 2 and 3 ) highly vascular tumours were found displacing adjacent hepatic arterial branches. Irregular pools of contrast medium and irregular pathological vessels were present within the tumours, and in the late films a persistent dense tumour blush was visible (Figs. 1, 2, and 3). In Case 1 a tumour mass was not demonstrated; the branches of the hepatic artery showed marked tortuosity with narrowing of their lumina, resulting in a "corkscrew" appearance thought to be due to cirrhosis, but

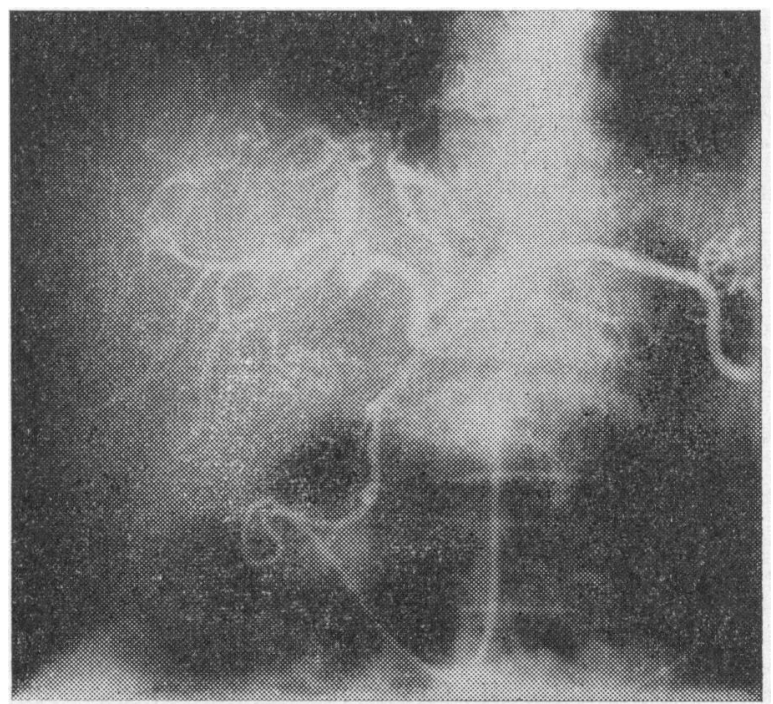

FIG. 1.-Coeliac angiogram (Case 2), showing displacement of normal vessels by tumours in the right and left lobes of the liver. 
the diffusely opacified liver shadow during the phase of sinusoidal filling was greatly enlarged.

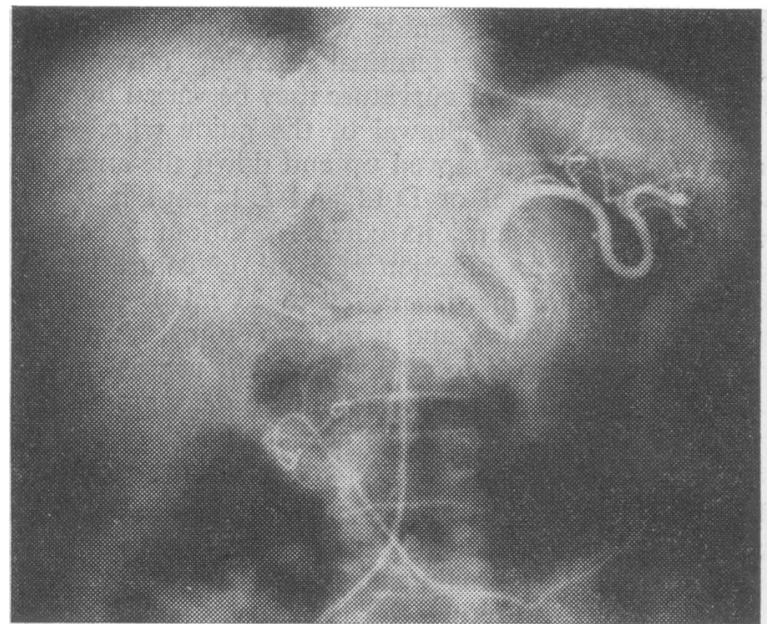

FIG. 2.-Later phase of coeliac angiogram in Case 2, showing pathological circulation at sites of tumour.

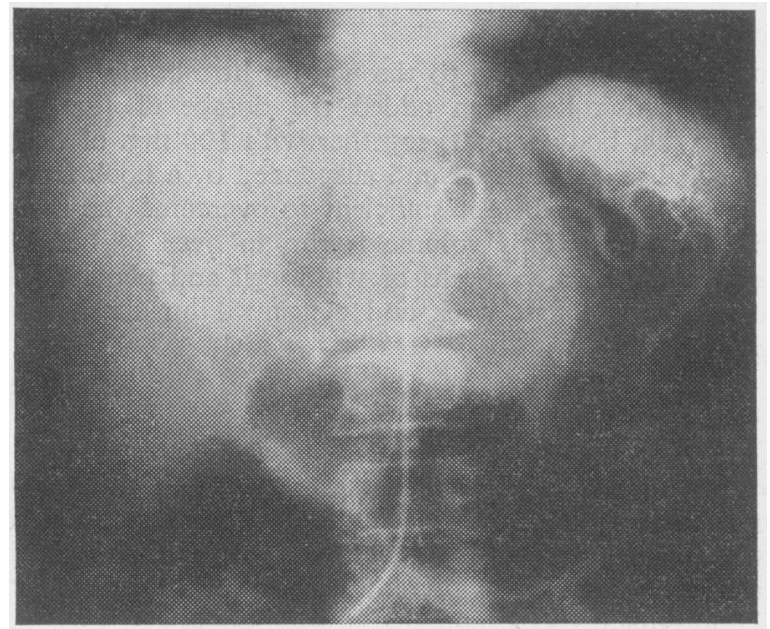

FIG. 3.-Tumour blush revealed in final films of Case 2.

\section{Discussion}

It is probable that long-term control of primary liver cancer, particularly in children (Borman et al., 1961; McWilliam, 1961), is best obtained by hepatic lobectomy. However, when pain is a prominent feature of the illiness in adults, as in two of the three cases reported here, and where surgery is not feasible prolonged palliation of the disease is important. The technique described here provides a simple method of producing this result. The infusion catheter may be introduced into the hepatic artery through one of its branches at operation (Watkins and Sullivan, 1964) or via the brachial or femoral arteries by direct exposure or percutaneous puncture of these vessels (Byron et al., 1961 ; Clarkson et al., 1962 ; Rochlin and Smart, 1966). Laparotomy provides a method for introducing a catheter for prolonged intermittent perfusion by means of a pump, but this may be a hazardous undertaking in an already sick patient, and unless preoperative angiography has delineated the anatomy of the hepatic artery the catheter may be incorrectly placed.

Anomalies of the blood supply to the liver are not uncommon: the hepatic artery may have an anomalous origin from branches of the coeliac axis ; it may also arise from the superior mesenteric artery or direct from the aorta. There is usually a single common hepatic antery, but occasionally a secondary artery may arise from the left gastric or superior mesenteric artery (Odnoralov, 1964). Any such anomaly should be recog- nized from the angiographic appearances and when present will necessitate repositioning of the catheter.

The brachial artery may be used for catheterization, but this 0 usually requires direct exposure of the vessel for introduction of the catheter, and the relatively small size of the artery carries $\mathbb{\infty}$ an increased risk of thrombosis while the catheter is in position. $C$ Percutaneous puncture of the femoral artery is simple and the larger size of this vessel renders thrombosis less likely.

No difficulty was encountered in catheterization of the coeliac axis in the three cases reported here. In other cases, particu- $\frac{\bar{F}}{\bar{N}}$ larly in the elderly, successful catheterization has occasionally $\frac{\text { ? }}{\supset}$ been prevented by atheromatous disease in the iliac arteries. $\triangle$ In these cases successful percutaneous catheterization has been performed via the axillary artery.

The importance of preoperative angiography has already been stressed, and the results of treatment and the position of $\vec{\omega}$ the catheter may be assessed by further angiography. For these $\frac{O}{D}$ reasons a large catheter is advisable. In these three cases no $\frac{0}{3}$ trouble from thrombosis of the femoral artery occurred even though the catheter was in position for as long as four weeks $i$ in Case 2. Bleeding occurred in Case 3 and may have been related to his poor hepatic function. It was easily controlled $\dot{\omega}$ by digital pressure. No complication apart from this bleeding $\stackrel{+}{\sigma}$ occurred as a result of the infusion, and hepatic function did $\mathrm{O}$ not deteriorate in any of the cases.

Limiting factors in achieving adequate dosage by this route $\vec{\circ}$ are depression of bone marrow and deterioration of liver cell function. Regular white cell counts and estimation of plasma bilirubin, aspartate aminotransferase, and albumin were made and no change occurred during treatment lasting three weeks $\vec{\varphi}$ in Case 1 and four weeks in Case 2. In Case 3 treatment was $\infty$ curtailed by the appearance of symptoms considered to be due $\square$ to metastases, which are not known to be influenced by treatment.

The results of treatment may be assessed by relief of pain, by reduction in clinical size of the liver, and by serial angio- $\mathbb{D}$ grams and gamma scans. All patients responded well by both $\stackrel{2}{\Rightarrow}$ clinical criteria. The limited experience of these cases suggests that angiography before and after treatment may be more helpful than scanning in documenting the change within the liver; this investigation involves no additional hardship for a patient who already has a catheter in his coeliac axis.

The long-term effects of this therapy are difficult to assess until more cases have been treated. Berman (1951), in his $\frac{5}{3}$ monograph on hepatoma in Africans, gave a prognosis of four months from the time of diagnosis. Croft and Wilkinson 0 (1965) found that three out of four were dead in six months; Nelson et al. (1966) and Patton and Horn (1964) found an 욱 average survival of six months. Chan (1967) reported on the N use of intra-arterial chemotherapy in 13 cases of unresectable hepatoma by means of cannulation of the hepatic artery at operation. He noted relief from pain in nearly $80 \%$ of cases, but the average survival time was only 3.3 months. At the time of writing one of our patients (Case 2) was alive 20 months $\omega$ after symptoms began, while another (Case 1) died seven? months after their onset.

Hepatoma may be commoner than has been supposed. Though in Canada and the United States it occurs most com-? monly in a previously normal liver (only $38.5 \%$ of the cases of Nett and Gilbert (1966) had cirrhosis and as few as $2.6 \% \stackrel{\vec{D}}{\mathrm{D}}$ of Nelson et al., 1966), in Britain the disease is diagnosed most $\frac{?}{\Phi}$ often in patients previously known to be cirrhotic. Retro- $₫$ spective studies have suggested an incidence in cirrhiutics of about 19\% (Elkington et al., 1963 ; Loe, 1966). The presence 8 of a raised plasma alkaline phosphatase of non-osseous origing is regarded as a useful pointer to the possible presence of the disease (Nelson et al., 1966).

Nett and Giibert (1966) remark that "until recently the attitude of therapeutic nihilism associated with primary hepatic carcinoma made its diagnosis largely an academic exercise" 
and make a plea for earlier diagnosis in the hopes of greater success with surgical treatment. The potential benefit of intraarterial infusion of fluorouracil provides an additional reason for alertness.

\section{REFERENCES}

Ariel, I. M., and Pack, G. T. (1967). Cancer (Philad.), 20, 793.

Berman, C.' (1951). Primary Carcinoma of the Liver. London.

Borman, J. B., Harbott, A. J., and Morris, D. (1961). Brit. F. Surg., 49, 11

Brunschwig, A. (1963). Cancer (Philad.), 16, 277.

Byron, R. L., Perez, F. M., Yonemoto, R. H., Bierman, H. R., Gildenhorn, H. L., and Kelly, K. H. (1961). Surg. Gynec. Obstet., $112,689$.

Chan, K. T. (1967). Ann. roy. Coll. Surg. Engl., 41, 253.

Clarkson, B., et al. (1962). Cancer (Philad.), 15, 472.

Croft, P. B., and Wilkinson, M. (1965). Brain, 88, 427.

Elkington, S. G., McBrien, D. J., and Spencer, H. (1963). Brit. med. f., 2,1501 .

Gorgun, B., and Watne, A. L. (1967). Amer. f. Surg., 113, 363.

Lawrence, G. H., Grauman, D., Lasersohn, J., and Baker, J. W. (1966). Amer. F. Surg., 112, 200.
Lawrence, W., jun. (1965). In Progress in Clinical Cancer, edited by I. M. Ariel, 1, pp. 341-393. New York.

Lee, F. I. (1966). Gut, 7, 77.

Lin, T.-Y. (1966). Surg. Gynec. Obstet., 123, 289

MacDonald, R. A. (1957). Arch. intern. Med., 99, 266

McWilliam, P. K. A. (1961). Brit. 7. Surg., 49, 14.

Nelson, R. S., Elizalde, R. de, and Howe, C. D. (1966). Cancer (Philad.), 19,533 .

Nett, A. E., and Gilbert, J. A. L. (1966). Canad. med. Ass. F., 95, 45.

Ödman, P. (1958). Acta radiol. (Stockh.), Suppl. No. 159.

Odnoralov, N. I. (1964). In Vascular Roentgenology, edited by R. A Schobinger and F. F. Ruzicka, p. 368. New York.

Papac, R. J., and Calabresi, P. (1966). F. Amer. med. Ass., 197, 237.

Patton, R. B., and Horn, R. C. (1964). Cancer (Philad.), 17, 757.

Rochlin, D. B. and Smart, C. R. (1966). Surg. Gynec. Obstet., 123, 535

Scho 436.

Schweizer, O., and Howland, W. S. (1960). Surg. Gynec. Obstet., 110

61.
Seldinger, S. I. (1953). Acta radiol. (Stockh.), 39, 368.

Smith, R., and Sherlock, S. (1964). Surgery of the Gall Bladder and Bile Ducts, p. 220 . London.

Watkins, E., and Sullivan, R. D. (1964). Surg. Gynec. Obstet., 118, 3.

Wilson, R O., Love, J., Waken, J. K., and Gilrane, J. (1964). Amer. F. Surg., 108, 896.

\title{
Tetracycline-resistant Streptococci in South-west Essex : a Continuing Survey
}

\author{
M. H. ROBERTSON,* M.B., CH.B., M.C.PATH.
}

Brit. med.F., 1968, 3, 349-350

\begin{abstract}
Summary: Studies of beta-haemolytic streptococci isolated in material received from patients in Southwest Essex for a further period of three years showed that the overall percentage of tetracycline resistance has remained almost stationary, varying from $28 \%$ in 1963 through $35 \%$ in 1965 to $27 \%$ in 1967.

Ear, wound, and skin infections retain a high incidence of resistant strains, while sputa are still a relatively minor source of such organisms. Organisms isolated from throat swabs have an incidence of resistance closest to the mean.
\end{abstract}

\section{Introduction}

Tetracycline-resistant beta-haemolytic streptococci of Lancefield's groups A, B, and $G$ have been recorded in the general population from many parts of the world since 1960 and in this area of South-west Essex since 1963 (Robertson, 1965). These organisms probably became important in the United Kingdom in 1961, a little later than in the United States (Dadswell, 1967a).

Dadswell published an eight-year summary of their isolation from patients in an ear, nose, and throat hospital and pointed out the rapid rise in incidence in the years 1961 and 1962 ; he also expressed the view that any further rise is likely to be slow.

The present communication deals with the incidence of such strains isolated in two general hospitals and from generalpractice patients over the period 1963-7 and continues a series previously reported (Robertson, 1965).

The sources of material and the methods used are identical, but the population covered has risen by approximately 20,000 . Sensitivity was estimated by means of paper discs (Oxoid) containing $10 \mu \mathrm{g}$. of tetracycline, $10 \mu \mathrm{g}$. of erythromycin, $10 \mu \mathrm{g}$.

* Consultant Bacteriologist, St. Margaret's Hospital, Epping, and Princess Alexandra Hospital, Harlow, Essex. of chloramphenicol, or 1.5 units of penicillin on blood agar plates incubated overnight. Organisms were recorded as resistant if they grew right up to these discs. Minimal inhibitory concentrations (M.I.C.) were estimated as previously reported and bactericidal levels were obtained by plating out the tubes showing no growth and recording the lowest concentration of tetracycline from which there was no growth.

\section{Results}

Of 2,249 strains of beta-haemolytic streptococci isolated over the five-year period $715(31.8 \%)$ were tetracycline-resistant. The Table shows their sources and the numbers isolated from each site. Percentages are recorded where the isolations exceed or closely approximate to 50 .

A breakdown of isolations from material examined in the last three-year period, sent by general practitioners ( 528 strains) and from inpatients (525 strains), outpatients (367 strains), and nurses (100 strains), showed the percentages of resistant strains to be $35.3 \%$ from the general-practitioner specimens, $33.5 \%$ from inpatients, $29 \%$ from outpatients, and $16 \%$ from the nurses. These figures show a slight fall in the percentages from general practice and nurses and a slight rise in the percentages from both inpatients and outpatients, compared with the years 1963 and 1964.

Lancefield-grouping of 123 strains from the last three years showed $51 \%$ to belong to group $\mathrm{A}, 5 \%$ to $\mathrm{B}, 12 \%$ to $\mathrm{C}$, $7 \%$ to $\mathrm{D}, 10 \%$ to $\mathrm{G}$, and $13 \%$ to none of these groups. The figures are expressed to the nearest whole number. They show a fall in the proportion of group A strains, but the numbers involved are too small to be significant.

Antibiotic sensitivity results are as follows for the second period of the survey. All strains were fully sensitive to penicillin, with the exception of nine which all proved to belong to Lancefield's group D. These nine strains produced small zones around the penicillin discs. Other strains which were obviously 